\title{
Total Foliar Nutrition Applied On European Hazelnut
}

\author{
Cristofori Valerio(1)* ${ }^{*}$ Bortolato Alberto(2), Valentini Rachele(1), Stelliferi Romeo(3), Valentini Benedetto(4) \\ (1) Department of Agriculture and Forestry Sciences, University of Tuscia, Via S. Camillo de Lellis snc, \\ 01100 Viterbo, Italy \\ (2) BMS Micro-Nutrients s.r.l., Rijksweg 32, 2880 Bornem, Belgium \\ (3) Farm "Il Casalone di Norchia" - 01019 Vetralla (VT), Italy \\ (4) Technical assistance "ASSOFRUTTI", Loc. San Valentino - 01032 Caprarola (VT), Italy
}

\begin{abstract}
In Lazio region, the widespread hazelnut monoculture could play a considerable role in mineral pollution. Currently, it is necessary to define sustainable nutritional management of hazelnut orchards in these areas. With the aim of limiting losses of mineral elements by production systems, an experiment was initiated based on the management of total foliar nutrition of hazelnut orchards. The trial was conducted in an adult orchard of hazelnut cultivated with 'Tonda Gentile Romana' and 'Nocchione'. Two randomized experimental theses were subjected to foliar nutrition conducted in several applications of macro and micronutrients during the growing season (thesis A, 4 treatments; thesis B, 3 treatments), in comparison with controls fertilized with the traditional technique of a single application in early spring. The measurements and observations focused on the vegetative traits of the trees, the leaf analysis at the beginning and the end of July, and the production and nut and kernel characteristics. The data collected during three years of investigation and the leaf analysis based on the determination of the content of nitrogen, phosphorus, potassium, calcium, magnesium, boron and iron, showed no significant differences between the compared theses, noting the appropriateness of total foliar nutrition in the period of the trial.
\end{abstract}

Keywords: Corylus avellana L., leaf analysis, macronutrients, micronutrients, foliar fertilization

\section{INTRODUCTION}

The long-term widespread hazelnut monoculture in Latium could play a significant role in the mineral pollution found in the area. For example, the hazelnut fertilization of the orchards located within the protected area of the Natural Reserve of Vico Lake (Viterbo province) has contributed to the recent eutrophication of lake waters. This actual condition has been very marked during the eighties, and is also a result of erosion which occurred when the orchards were not managed with cover crops (Cristofori et al., 2013).

Currently, it is necessary to define a sustainable nutrition management of the hazelnut orchards in these areas. Furthermore, the complex overlapping of vegetative and reproductive activity in a short period of the annual cycle makes hazelnut yield and quality highly dependent on a correct nutritional support (Bignami et al., 2005).

Nitrogen is the most important component in the mineral nutrition of the hazelnut (Tous et al., 1994; Olsen, 1997). The foliar application of calcium also plays an important role during the kernel filling stage (Cakca and Sanguankeo, 2014). Recently, trials were conducted to develop optimized protocols for hazelnut nutrition, including foliar applications, in Italy on the cultivar 'Tonda Gentile delle Langhe' (Roversi, 2011; Pansecchi et al., 2014), in Oregon on different cultivars (Olsen and Cakca, 2009), and in Chile on the cultivar 'Barcelona' (Ellena et al., 2014).

With the aim of limiting losses of mineral elements by the hazelnut agro-ecosystem and for evaluating the sustainable management of orchard nutrition only through foliar applications similar to vineyards (Belvini et al., 2006), a first experiment based on the management of total foliar nutrition of an adult hazelnut orchard was initiated and carried out in Viterbo province on cultivars 'Tonda Gentile Romana' and 'Nocchione' over 2012-2014. 


\section{MATERIAL AND METHODS}

\section{Plant material}

The trial was conducted in mature orchard of 'Tonda Gentile Romana' and 'Nocchione', located in Viterbo province, Italy. Two experimental plots per cultivar (Thesis A, Thesis B; each 5,000 $\mathrm{m}^{2}$ ) were subjected to foliar nutrition in several applications of macro and micronutrients [Kappa M 22-8$12(\mathrm{Mn})$; Fructol NF 5-8-15 (Mg, S) (B) (Fe) (Mo) (Zn)], during three growing season (Table 1), in comparison with controls fertilized with the traditional technique of a single application at the beginning of spring $(600 \mathrm{~kg} / \mathrm{ha}$ of NPK $20-10-10)$.

The trees were spaced $4 \mathrm{~m} \times 5 \mathrm{~m}$ and grown as multi-stemmed plants trained as an open vase, not irrigated, and managed with standard orchard management techniques and an integrated pest management plan.

On average, the soil characteristics tested in the two theses and in the control were: medium texture-clay, pH 5.8, organic matter content $2.2 \%$, with low limestone and calcium content.

\section{Yield, nut and kernel traits and foliar analysis}

The measurements and observations focused on yield, the nut and kernel traits, and leaf analysis with observations at the beginning and end of July.

Production was tested at harvest time, collecting the nuts from each experimental plot and cultivar using a vacuum machine, and mechanically drying and cleaning the nuts before weighing the yield.

The nut and kernel traits were recorded according to De Salvador et al., (2005), testing a 200 nuts sample for each thesis and cultivar during the three year investigation.

The leaf analyses were carried out by collecting adult leaves from six different and randomized trees per experimental plot and cultivar on $4^{\text {th }}$ and $24^{\text {th }}$ July 2013 (second year of the trial). A sub-leaf sample of 50 leaves per plot, cultivar, and data collection was used for leaf area measurements using an area meter (LI-3100; LICOR, Lincoln, NE, USA) calibrated to $0.01 \mathrm{~cm}^{2}$. For the leaf dry matter content tested, samples were dried at $103 \pm 2 \circ \mathrm{C}$ until a constant weight was achieved. The other subleaf samples were delivered to the Assofrutti Analysis Lab for leaf analysis consisting of nitrogen, phosphorus, potassium, calcium, magnesium, boron and iron contents, adopting official analysis methods (Kjeldahl for nitrogen, Vanadate-molybdate for phosphorus, F-AAS for potassium, calcium, magnesium and iron, G-AAS for boron).

At the end of the trial the soil characteristics for each experimental plot were tested to evaluate the possible influence on soil fertility where total leaf fertilization was applied.

\section{Statistical analysis}

Analysis of variance was performed managing the cultivars data separately, and focused on nut and kernel traits and on foliar analysis data to estimate the effects of thesis and year using the SYSTAT MGLH procedure (Wilkinson, 1998). The least significant difference (L.S.D. $p=0.05$ ) for the comparison of the means was then calculated.

\section{RESULTS AND DISCUSSION}

The cumulative production, expressed as ton ha-1, showed slight differences between experimental plots, without significance related to the effect of the fertilization treatment (Figure 1). Thesis A expressed in the three years of investigation showed slightly higher yield than control and Thesis B for both cultivars (slightly more than 8 ton ha-1 for 'Nocchione' and almost 7 ton ha-1 for 'Tonda Gentile Romana'). However, this difference does not seem to be linked to the effect of the fertilization treatment, which did not show yield contractions in the leafy fertilizers theses compared to conventional fertilized control. 
Even the cumulative production did not show any significant differences over the theses considered, although the production was higher for 'Nocchione', confirming the production for this cultivar (Cristofori et al., 2014).

Table 2 shows the nut and kernel traits of the cultivar 'Tonda Gentile Romana', expressed as an average value of the three-year of investigation. The theses treated with total leaf nutrition showed a nut weight slightly less than in the control, while the shell weight showed higher values for theses A and B. There was a higher differences for thesis A, subjected to four leaf nutrition applications, which showed an average percent kernel of $46 \%$, higher by almost two percent points compared to the control.

For the cultivar 'Nocchione', it was discovered that the theses treated with total leafy fertilization had significantly higher nut and shell weight than the control (Table 3). Furthermore, Thesis A showed a significantly higher percent kernel in respect the control, greater than one percent point $(39.2 \%$ and $38 \%$ for Thesis A and control, respectively). For both cultivars, the year of investigation has shown only slight differences.

The main leaf mineral contents of 'Tonda Gentile Romana', respectively determined at the beginning and end of July 2013, are shown in table 4.

The nitrogen content ranged from 17 to $19 \mathrm{mg} \mathrm{g}^{-1} \mathrm{~d}$.w. in the theses for the two different sampling dates, without highlighting significant differences. Phosphorous content showed slight variations related to the collection time and was slightly higher at the end of July with average values of $1.5 \mathrm{mg} \mathrm{g}-$ 1 d.w. Potassium content showed differences at the beginning of July compared to thesis B $(8.23,8.41$ and $6.92 \mathrm{mg} \mathrm{g}^{-1} \mathrm{~d} . \mathrm{w}$. in control, thesis $\mathrm{A}$ and B, respectively), whereas those differences contracted considerably at the end of July (Table 4). Calcium content showed a tendency very similar to that observed for potassium, without statistical differences. The magnesium content showed a tendency similar to that of nitrogen, with a significance linked to the effect of the sampling collection time. Boron and iron showed a significant increase in value at the end of July compared to the beginning of the month, ranging from 60 to $170 \mu \mathrm{g} \mathrm{g}^{-1}$ d.w., respectively, in early July at 80-100 and 180-230 $\mu \mathrm{g} \mathrm{g}^{-1}$ d.w. in late July.

Similarly to the 'Tonda Gentile Romana', table 5 shows the mean values of the main mineral elements determined in the leaves of the cultivar 'Nocchione'. Nitrogen content also varied in this cultivar from 17 to $20 \mathrm{mg} \mathrm{g}^{-1} \mathrm{~d}$.w. in the comparative theses for the two different sampling dates, without highlighting significant differences. The phosphorus content showed slight variations related to sampling time, and in this case it was slightly higher at the end of July with average values of 1.5-1.8 $\mathrm{mg} \mathrm{g}^{-1}$ d.w. Potassium content, although no significance was attached to the effect of the treatment and the sampling time, was more present in theses A and B compared to the control in early July, and then increased the concentration at the end of July (Table 5). Calcium content showed slight variations related both to the effect of the treatment and to the sampling time, although not significant, with values between 11 and $15 \mathrm{mg} \mathrm{g}^{-1} \mathrm{~d}$.w. Magnesium content was constant in all the theses and sampling dates with average values of $2 \mathrm{mg} \mathrm{g}^{-1} \mathrm{~d}$.w.. Also for the 'Nocchione', boron and iron showed an increase in values at the end of July compared to the beginning of the month.

The mean values of the leaf mineral content observed at the beginning and end of July can be adopted for determining the optimal nutritional status for the two cultivars in the environment of the trial.

The average nitrogen content in the two cultivars remained constant in July with values of about $18 \mathrm{mg} \mathrm{g}^{-1} \mathrm{~d} . \mathrm{w}$. Phosphorus showed a slight increase at the end of July, ranging from 1.2 to $1.5 \mathrm{mg}$ $\mathrm{g}^{-1} \mathrm{~d}$.w. in both cultivars. Potassium, calcium and magnesium, similar to nitrogen, had constant mean concentrations in July with average values of 8,14 , and $2 \mathrm{mg} \mathrm{g}^{-1}$ d.w., respectively. Boron showed a slight increase in content at the end of July passing from mean values of 50-60 $\mu \mathrm{g} \mathrm{g}^{-1} \mathrm{~d}$.w. in early July to $80 \mu \mathrm{g} \mathrm{g}{ }^{-1} \mathrm{~d}$.w. Iron was the only element that showed significant differences among cultivars in its mean values; while in the cultivar 'Tonda Gentile Romana' increments ranging from $160 \mu \mathrm{g} \mathrm{g}-1 \mathrm{~d} . \mathrm{w}$. in early July to $210 \mu \mathrm{g} \mathrm{g}^{-1} \mathrm{~d}$.w. were seen at the end of July, in the case of 'Nocchione' the mean content was $210-220 \mu \mathrm{g} \mathrm{g}^{-1} \mathrm{~d} . w$. in all the samples considered.

No differences related to the treatments were found for the leaf area and for the leaf dry matter content (data not shown).

The values of the main mineral elements in the leaves of both cultivars were in according with those available in the literature (Canali et al., 2005), and can be adopted for foliar diagnostic analysis 
in combination with the dynamic of mineral contents revealed in the kernel during the filling stage (Cristofori et al., 2015).

\section{CONCLUSIONS}

The principles of foliar nutrition carried out in these experiments base their foundations on the proven eco-physiological condition that the elements are absorbed, digested, and used by the tree and not dispersed in the environment.

The data collected during three years of investigation and the leaf analysis based on the determination of the content of major macro and micro nutrients attests the appropriateness of total foliar nutrition in the period of the trial. Furthermore, the chemical analysis of the soils carried out ante- and posttrials did not reveal significant differences in terms of soil fertility. On the other hand, the protocol applied on Thesis A seems to be appropriate for applications in commercial orchards, mainly to be promoted in combination with organic fertilizers on old and stressed hazelnut fields to increase the organic matter content in the soil.

\section{ACKNOWLEDGEMENTS}

This work was supported by the Italian Ministry of Agricultural and Forestry Policy (MIPAAF 2011D.D. 17304 “MI.F.CO.L. - Miglioramento della Filiera Corilicola Laziale”).

\section{Literature cited}

Belvini, P., Bavaresco, L., and Della Costa L. (2006). Concimazione di produzione per via fogliare nella vite. Vignevini, 10/2006: 67-70.

Bignami, C., Cammilli, C., Moretti, G., and Sallusti, L. (2005). Growth Analysis and Nitrogen Dynamics in Hazelnut 'Tonda Gentile Romana'. Acta Hortic. 686: 193-200. https://doi.org/10.17660/ActaHortic.2005.686.26.

Cacka, J., and Sanguankeo, P. (2014). Calcium influence on hazelnut quality and yields in Oregon. Acta Hortic., 1052: 187-193. https://doi.org/10.17660/ActaHortic.2014.1052.24.

Canali, S., Nardi, P., Neri, U., and Gentili, A. (2005). Leaf Analysis as a tool for evaluating nutritional status of Hazelnut orchards in central Italy. Acta Hort. 686: p. 291-296. https://doi.org/10.17660/ActaHortic.2005.686.41.

Cristofori V., Silvestri C., Alimento V., and Rugini E. (2013). Indagine sulla fertilità dei suoli coltivati nella caldera del lago di Vico per una gestione sostenibile delle colture. Corylus \& co., Anno IV, n. 1/2013: 39-51. (ISSN 2038-8292).

Cristofori V., Bizzarri S., Silvestri C., and De Salvador F.R. (2014). First evaluations on vegetative and productive performance of many hazelnut cultivars in Latium region. Acta Hortic., 1052: 91-97. https://doi.org/10.17660/ActaHortic.2014.1052.11.

Cristofori V., Bertazza G., and Bignami C. (2015). Changes in kernel chemical composition during nut development of three Italian hazelnut cultivars. Fruits 70 (5): 311-322. https://doi.org/10.1051/fruits/2015025.

De Salvador F.R., Bizzarri S., Bignami C., Cristofori V., Temperini O., De Benedetto A., and Giorgioni M. (2005). Monografia di cultivar di nocciolo. Tipolitografia C.S.R. (RM), pp. 47.

Ellena, M., Sandoval, P., Montenegro, A., Gonzalez , A., and Azocar, G. (2014). Effect of foliar nutrient applications on fruit set in "Chilean Barcelona" hazelnut, in southern Chile. Acta Hortic., 1052: 231-234. https://doi.org/10.17660/ActaHortic.2014.1052.10.

Pansecchi , A., Roversi , A., and Malvicini, G.L. (2014). Some years of trials on the effectiveness of hazelnut foliar fertilization. Acta Hortic., 1052: 195-199. https://doi.org/10.17660/ActaHortic.2014.1052.25.

Olsen, J. (1997). Nitrogen management in Oregon hazelnuts. Acta Hortic., 445: 263-268.

Olsen, J.L., and Cacka, J.F. (2009). Foliar fertilizers on hazelnuts in Oregon, USA. Acta Hortic., 845: $349-352$. https://doi.org/10.17660/ActaHortic.2009.845.53.

Roversi, A., 2011. Concimazione del nocciolo. L'Informatore Agrario 49: 61-65.

Tous, J., Girona, J., and Tasias, J. (1994). Cultural practices and costs in hazelnut production. Acta Hortic., 351: $395-418$. https://doi.org/10.17660/ActaHortic.1994.351.44.

Wilkinson L. (1998). SYSTAT, version 8.0. SPSS, Chicago. 


\section{Tables}

Table 1. Experimental designs for total foliar nutrition of hazelnut (Cvs 'Tonda Gentile Romana' and 'Nocchione') during the three year investigation (2012-14).

\begin{tabular}{ccllc}
\hline $\begin{array}{c}\text { TREATMENT } \\
\text { THESIS A }\end{array}$ & NPK & AMOUNT & PERIOD & $\begin{array}{c}\text { PHYTOSANITARY } \\
\text { TREATMENT }\end{array}$ \\
\hline $\mathbf{1}$ & Kappa - M (21-12-18) & $5.0 \mathrm{~kg} \mathrm{ha}^{-1}$ & End of April & No \\
$\mathbf{2}$ & Fructol NF (5-8-15) & $2.5 \mathrm{~kg} \mathrm{ha}^{-1}$ & End of May & Yes \\
$\mathbf{3}$ & Fructol NF (5-8-15) & $2.5 \mathrm{~kg} \mathrm{ha}^{-1}$ & Mid June & Yes \\
$\mathbf{4}$ & Fructol NF (5-8-15) & $3.0 \mathrm{~kg} \mathrm{ha}^{-1}$ & Early July & No \\
\hline TREATMENT & NPK & AMOUNT & PERIOD & PHYTOSANITARY \\
THESIS B & & & & TREATMENT \\
\hline $\mathbf{1}$ & Kappa - M (21-12-18) & $5.0 \mathrm{~kg} \mathrm{ha}^{-1}$ & End of April & No \\
$\mathbf{2}$ & Fructol NF (5-8-15) & $2.5 \mathrm{~kg} \mathrm{ha}^{-1}$ & End of May & Yes \\
\hline & Fructol NF (5-8-15) & $2.5 \mathrm{~kg} \mathrm{ha}^{-1}$ & Mid June & Yes \\
\hline
\end{tabular}

Table 2. Nut and kernel traits expressed as the three-year mean (2012-14) from the cultivar 'Tonda Gentile Romana' treated with total foliar nutrition.

\begin{tabular}{ccccc}
\hline THESIS & Nut & Shell & Kernel & \% Kernel \\
& $(\mathrm{g})$ & $(\mathrm{g})$ & $(\mathrm{g})$ & \\
\hline Control & 2.88 & 1.29 & 1.59 & 44.35 \\
A & 2.52 & 1.17 & 1.35 & 45.80 \\
B & 2.60 & 1.21 & 1.42 & 44.50 \\
\hline \multicolumn{5}{r}{ Effects (L.S.D. P=0.05) } \\
\hline Year & 0.13 & 0.35 & 0.07 & 0.68 \\
\hline
\end{tabular}


Table 3. Nut and kernel traits expressed as the three-year mean (2012-14) from the cultivar 'Nocchione' treated with total foliar nutrition.

\begin{tabular}{ccccc}
\hline THESIS & Nut & Shell & Kernel & \% Kernel \\
& $(\mathrm{g})$ & $(\mathrm{g})$ & $(\mathrm{g})$ & \\
\hline Control & 2.54 & 0.91 & 1.63 & 37.97 \\
A & 2.58 & 1.03 & 1.56 & 39.27 \\
B & 2.78 & 1.09 & 1.70 & 38.54 \\
\hline & & Effects (L.S.D. P=0.05) & \\
\hline Thesis & 0.17 & 0.36 & 0.11 & 0.61 \\
Year & 0.12 & 0.21 & 0.08 & 0.45 \\
\hline
\end{tabular}

Table 4. Leaf analysis of the cultivar Tonda Gentile Romana: comparison of the treatments.

\begin{tabular}{|c|c|c|c|c|c|c|c|c|c|}
\hline $\mathrm{CV}$ & Date & Thesis & $\begin{array}{c}\text { Nitrogen } \\
\left(\mathrm{mg} \mathrm{g}^{-1}\right. \\
\mathrm{dw})\end{array}$ & $\begin{array}{l}\text { Phosphorus } \\
\left(\mathrm{mg} \mathrm{g}^{-1} \mathrm{dw}\right)\end{array}$ & $\begin{array}{l}\text { Potassium } \\
\left(\mathrm{mg} \mathrm{g}^{-1} \mathrm{dw}\right)\end{array}$ & $\begin{array}{c}\text { Calcium } \\
\left(\mathrm{mg} \mathrm{g}^{-1} \mathrm{dw}\right)\end{array}$ & $\begin{array}{c}\text { Magnesium } \\
\left(\mathrm{mg} \mathrm{g}^{-1} \mathrm{dw}\right)\end{array}$ & $\begin{array}{c}\text { Boron } \\
\left(\mu \mathrm{g} \mathrm{g}^{-1} \mathrm{dw}\right)\end{array}$ & $\begin{array}{c}\text { Iron } \\
\left(\mu \mathrm{g} \mathrm{g}^{-1} \mathrm{dw}\right)\end{array}$ \\
\hline & & Control & 19.15 & 1.21 & 8.23 & 15.74 & 2.10 & 64.99 & 159.70 \\
\hline \multirow[t]{3}{*}{ TGR } & $4^{\text {th }}$ July & A & 17.91 & 1.04 & 8.41 & 15.06 & 2.02 & 60.11 & 173.14 \\
\hline & & B & 17.78 & 1.17 & 6.92 & 10.43 & 1.80 & 66.77 & 167.91 \\
\hline & & Control & 18.02 & 1.48 & 8.67 & 16.05 & 2.27 & 101.57 & 178.98 \\
\hline \multirow[t]{2}{*}{ TGR } & 24th July & A & 17.29 & 1.41 & 7.82 & 14.01 & 2.08 & 80.73 & 233.73 \\
\hline & & B & 19.35 & 1.68 & 7.83 & 14.96 & 2.14 & 73.11 & 209.94 \\
\hline \multicolumn{10}{|c|}{ Effects (L.S.D. P=0.05) } \\
\hline & Thesis & & NS & NS & 0.74 & NS & NS & NS & NS \\
\hline & Date & & NS & 0.22 & NS & NS & 0.18 & 20.16 & 33.11 \\
\hline
\end{tabular}

Table 5. Leaf analysis of the cultivar Nocchione: comparison of the treatments.

\begin{tabular}{|c|c|c|c|c|c|c|c|c|c|}
\hline $\mathbf{C V}$ & Date & Thesis & $\begin{array}{c}\text { Nitrogen } \\
\left(\mathrm{mg} \mathrm{g}^{-1}\right. \\
\mathrm{dw})\end{array}$ & $\begin{array}{c}\text { Phosphorus } \\
\left(\mathrm{mg} \mathrm{g}^{-1} \mathrm{dw}\right)\end{array}$ & $\begin{array}{l}\text { Potassium } \\
\left(\mathrm{mg} \mathrm{g}^{-1} \mathrm{dw}\right)\end{array}$ & $\begin{array}{l}\text { Calcium } \\
\left(\mathrm{mg} \mathrm{g}^{-1} \mathrm{dw}\right)\end{array}$ & $\begin{array}{c}\text { Magnesium } \\
\left(\mathrm{mg} \mathrm{g}^{-1} \mathrm{dw}\right)\end{array}$ & $\begin{array}{c}\text { Boron } \\
\left(\mu \mathrm{g} \mathrm{g}^{-1} \mathrm{dw}\right)\end{array}$ & $\begin{array}{c}\text { Iron } \\
\left(\mu \mathrm{g} \mathrm{g}^{-1} \mathrm{dw}\right)\end{array}$ \\
\hline & & Control & 18.28 & 1.39 & 6.73 & 14.48 & 2.04 & 56.93 & 201.33 \\
\hline \multirow[t]{3}{*}{$\mathbf{N}$} & $4^{\text {th }}$ July & A & 18.53 & 1.29 & 7.22 & 12.67 & 2.09 & 59.18 & 210.22 \\
\hline & & B & 16.58 & 1.07 & 8.16 & 12.76 & 2.14 & 41.47 & 216.17 \\
\hline & & Control & 20.50 & 1.82 & 8.08 & 13.53 & 2.12 & 88.69 & 189.05 \\
\hline \multirow[t]{2}{*}{$\mathbf{N}$} & $24^{\text {th }}$ July & A & 17.27 & 1.51 & 7.70 & 15.98 & 2.10 & 68.41 & 251.64 \\
\hline & & B & 18.07 & 1.45 & 7.84 & 11.28 & 2.00 & 73.00 & 248.66 \\
\hline \multicolumn{10}{|c|}{ Effects (L.S.D. P=0.05) } \\
\hline & Thesis & & n.s. & NS & n.s. & n.s. & n.s. & n.s. & n.s. \\
\hline & Date & & n.s. & 0.74 & n.s. & n.s. & n.s. & 21.13 & n.s. \\
\hline
\end{tabular}




\section{Figures}

Figure 1. Cumulative production of the three-year trial (2012-14): comparison of the treatments.

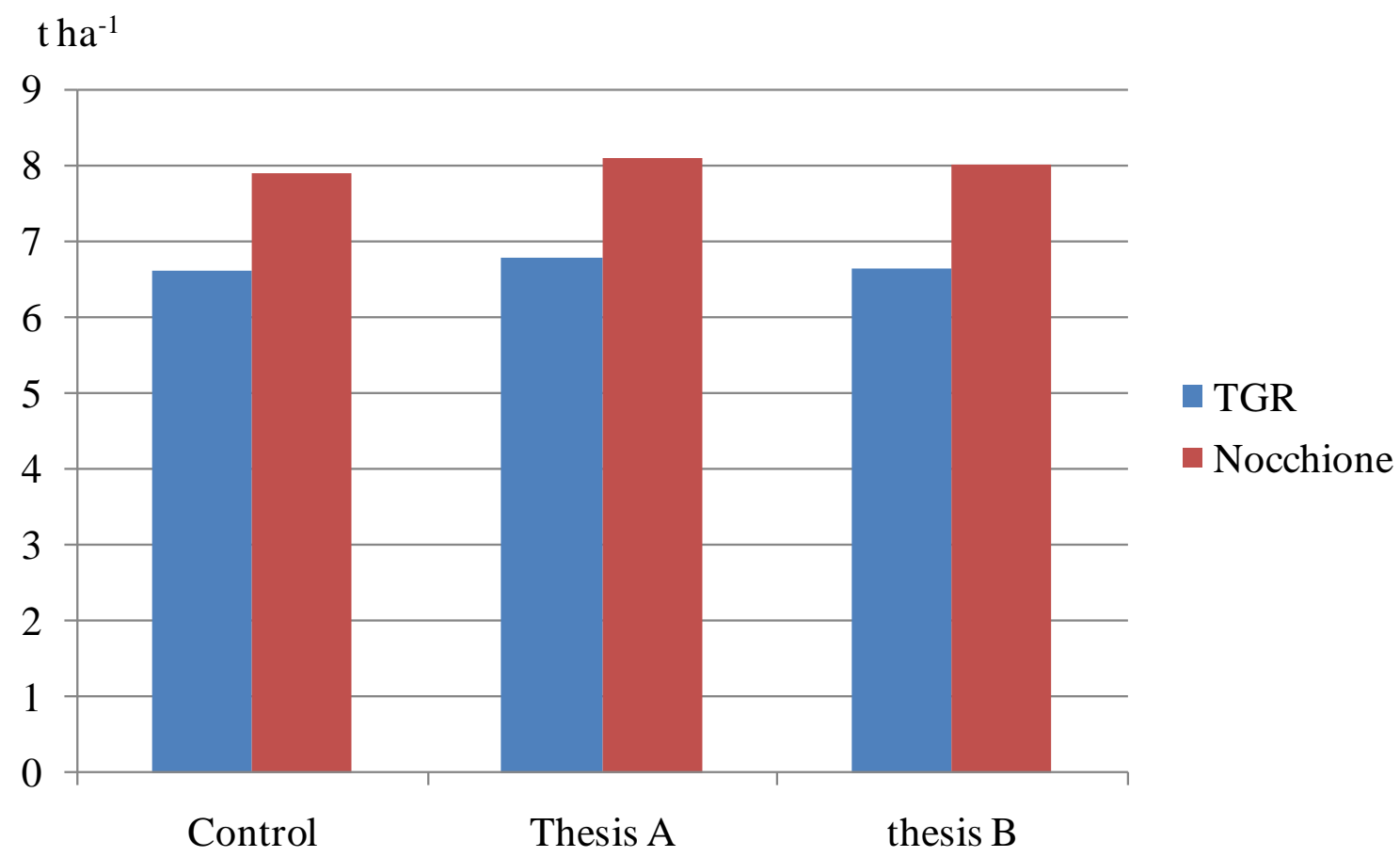

